\section{PS-098 HAEMODYNAMIC AND METABOLIC EFFECTS OF A NEW PAEDIATRIC DOBUTAMINE FORMULATION IN HYPOXIC NEWBORN PIGLETS}

IV Mielgo, ${ }^{1}$ A Valls-i-Soler, ${ }^{1} \mathrm{~J}$ Lopez de Heredia, ${ }^{1} \mathrm{C}$ Rey-Santano, ${ }^{2}$ on behalf of NeoCirc Consortium. Neonatal Research Unit, Hospital Universitario Cruces, Barakaldo, Spain; ${ }^{2}$ Neonatal Units, NeoCirc Consortium, Spain

\subsection{6/archdischild-2014-307384.393}

Background Using an age-appropriate new dobutamine formulation, the aims of the study were: to validate superior vena cava flow (SVCF) as a marker of cardiac output (CO), and to study drug-related changes in haemodynamics and oxygen metabolism in response to escalating doses of dobutamine in hypoxic neonatal piglets.

Methods 2-days-old-piglets were exposed to hypoxia (10-15\% oxygen) for $2 \mathrm{~h}$ followed by reoxigenation with $21-30 \%$ oxygen for $6 \mathrm{~h}$. After 60-min of reoxigenation, 18 piglets were randomised to: Control group, hypoxic animals without treatment, and $10-15 \mu \mathrm{g} / \mathrm{kg} / \mathrm{min}$ or $15-20 \mu \mathrm{g} / \mathrm{kg} / \mathrm{min}$ dose groups, each animal received two doses of dobutamine (Proveca Ltd.) during 30min with 60-min washout period between doses. All animals were monitored for arterial blood pressure (MABP), heart-rate (HR), CO, stroke-volume-index (SVI), systemic-vascular-resistance-index (SVRI), oxygen-delivery (OD), systemic consumption $\left(\mathrm{VO}_{2}\right)$ and fractional-tissue-oxygen extraction (FTOE). In three animals an ultrasonic perivascular flow probe was placed around superior vena cava to continuously measure SVCF. Statistics: Mean \pm SD, ANOVA, $\mathrm{p}<0.05$.

Result A good positive correlation was observed between SVCF and CO. Hypoxia resulted in a significant decreased on CO, SVI, SVRI and MABP. All dobutamine doses improved significantly HR, CO and SVRI without changes in SVI and MABP. All doses increased OD but only $10-15 \mu \mathrm{g} / \mathrm{kg} / \mathrm{min}$ increased $\mathrm{VO}_{2}$ without changes in FTOE.

Conclusion The new dobutamine formulation targeted to support neonatal cardiovascular function reveals a significant improvement of haemodynamic status, but dose-specific differences in metabolic response in hypoxic neonatal piglets. Further studies are needed to evaluate those drug effects in other vital organs. FP7-HEALTH-F5-2011 (n²82533).

\section{PS-099 TRANSITIONAL CHANGES IN CEREBRAL BLOOD VOLUME AT BIRTH}

B Schwaberger, G Pichler, C Binder, N Baik, B Urlesberger. Division of Neonatology, Medical University of Graz, Graz, Austria

\subsection{6/archdischild-2014-307384.394}

Background and aims Near-infrared spectroscopy (NIRS) is a non-invasive method to measure changes in the concentration of oxygenated $(\triangle \mathrm{O} 2 \mathrm{Hb})$ and deoxygenated haemoglobin $(\Delta \mathrm{HHb})$. Changes in total haemoglobin $(\Delta \mathrm{cHb}=\Delta \mathrm{O} 2 \mathrm{Hb}+\Delta \mathrm{HHb})$ give information on changes in cerebral blood volume (CBV). Moreover cerebral tissue oxygenation index (cTOI $=\Delta \mathrm{O} 2 \mathrm{Hb} / \Delta$ $\left.\mathrm{cHb}^{*} 100 \%\right)$ is detected.

The aim was to evaluate changes of CBV during postnatal transition in term newborns.

Methods This observational study was conducted at the Medical University Graz. Included were term infants without need for respiratory support after caesarean section. NIRS measurements were carried out with 'NIRO-200-NX' (Hamamatsu; Japan) over $15 \mathrm{~min}$.
Results 109 term infants (55 female) with mean gestational age of $39+0$ weeks ( \pm 7 days) and birth weight of $3245 \mathrm{~g}( \pm 441)$ were included.

CBV: Related to the baseline at $2 \mathrm{~min}$ of age (min), median (25th; 75 th percentiles) $\Delta \mathrm{cHb}$ was 0 micromoles $(\mu \mathrm{M})(-5 ; 4)$ at $3 \mathrm{~min},-1 \mu \mathrm{M}(-8 ; 5)$ at $5 \mathrm{~min},-7 \mu \mathrm{M}(-17 ; 0)$ at $10 \mathrm{~min}$, and -13 $\mu \mathrm{M}(-26 ; 1)$ at $15 \mathrm{~min} . \Delta \mathrm{cHb}$, representing the behaviour of $\mathrm{CBV}$, was slowly decreasing during transition period.

cTOI: Median (25th;75th percentiles) cTOI was 56\% $(50 ; 65)$ at $2 \mathrm{~min}, 57 \%(51 ; 64)$ at $3 \mathrm{~min}, 64 \%(58 ; 72)$ at $5 \mathrm{~min}, 74 \%$ $(69 ; 79)$ at $10 \mathrm{~min}$, and $72 \%(67 ; 78)$ at $15 \mathrm{~min}$. cTOI was slowly increasing from $2 \mathrm{~min}$ to $7 \mathrm{~min}$, reaching a steady state after 8 $\min$.

Conclusion In healthy newborns CBV was slowly decreasing over the whole study period. We hypothesise, that increasing left-to-right shunt via ductus arteriosus may account for decreasing CBV in this period. These findings add information for a better understanding of haemodynamic processes during transition.

\section{PS-100 BLOOD PRESSURE AND AORTIC DISTENSIBILITY AS EARLY MARKERS OF AN INCREASED CARDIOVASCULAR RISK IN PRESCHOOL CHILDREN BORN PRETERM - PRELIMINARY DATA}

${ }^{1}$ I Odri Komazec, ${ }^{1} \mathrm{~A}$ Posod, ${ }^{2} \mathrm{M}$ Schwienbacher, ${ }^{2} \mathrm{E}$ Schermer, ${ }^{1} \mathrm{~K}$ Kager, ${ }^{1} \mathrm{U}$ Pupp Peglow, ${ }^{2} \mathrm{D}$ Baumgartner, ${ }^{1} \mathrm{U}$ Kiechl-Kohlendorfer. 'Department of Pediatrics // (Neonatology), Innsbruck Medical University, Innsbruck, Austria; ${ }^{2}$ Department of Pediatrics III (Cardiology Pulmonology Allergology and Cystic Fibrosis), Innsbruck Medical University, Innsbruck, Austria

\subsection{6/archdischild-2014-307384.395}

Background and aims Numerous studies have shown that young adults born preterm have an increased risk of cardiovascular diseases. The aim of this study was to investigate which markers of an increased cardiovascular risk are already present at preschool age in children born preterm.

Methods In preschool children born preterm (gestational age less than 32 weeks) and healthy control subjects born at term, blood pressure was determined oscillometrically. Elastic properties of the ascending and descending aorta were calculated using computerised wall contour analysis out of transthoracic M-mode echocardiographic tracings.

Results 119 children were examined at 5 to 7 years of age (45 born preterm and 74 children born at term). Preschool children born preterm had significantly higher systolic blood pressure in comparison to preschool children born at term $(\mathrm{p}<0.001)$. Descending aorta distensibility was significantly decreased in preschool children born preterm in comparison to preschool children born at term $(p<0.05)$. Diastolic blood pressure, distensibility of the ascending aorta, and stiffness index of ascending and descending aorta did not differ significantly between the two groups.

Conclusions Children born preterm already have higher systolic blood pressure and decreased distensibility of the descending aorta in comparison to children born at term at preschool age. Preliminary data of this study underline the importance of a continuous and systematical follow-up of children born preterm. Further studies are needed to investigate the clinical relevance of these findings and to find possible preventive measures to lower cardiovascular risk of this population. 